Madrygal. Revista de Estudios Gallegos

ISSN: 1138-9664

\title{
La lengua gallega en el teatro de cordel portugués: estudio lingüístico ${ }^{1}$
}

\author{
Juan M. Carrasco González²
}

Recibido: 24 de outubro de 2019 / Aceptado: 20 de outubro de 2020

Resumen. El teatro de cordel portugués del siglo XVIII incluye algunas piezas con el personaje del gallego. Se trata de un retrato burlesco de los emigrantes gallegos que se desplazaban a Portugal en gran número, especialmente a la ciudad de Lisboa. En este trabajo se lleva a cabo el análisis de su lengua, que es un portugués con rasgos propios de la lengua gallega y salpicado de castellanismos de diverso tipo.

Palabras clave: gallego; historia de la lengua; teatro de cordel; literatura portuguesa.

\section{[gal] A lingua galega no teatro de cordel portugués: estudo lingüístico}

Resumo. O teatro de cordel portugués do século XVIII inclúe algunhas pezas co personaxe do galego. Trátase dun retrato burlesco dos emigrantes galegos que se desprazaban a Portugal en gran número, especialmente á cidade de Lisboa. Neste traballo lévase a cabo a análise da súa lingua, que é un portugués con trazos propios da lingua galega e salpicado de castelanismos de diverso tipo.

Palabras chave: galego; historia da lingua; teatro de cordel; literatura portuguesa.

\section{[en] The Galician Language in the Portuguese Teatro de Cordel: Linguistic Study}

Abstract. The Portuguese teatro de cordel of the eighteenth century includes some pieces with the character of the galician. It's about a burlesque portrait of the galician inmigrants that moved to Portugal in large numbers, especially to the city of Lisbon. In this paper the analysis of their language is carried out, which is a Portuguese with features of the Galician language and dotted with castillianisms of diverse kind.

Keywords: Galician Language; History of Language; Teatro de Cordel; Portuguese Literature.

Sumario. 1. La figura del gallego en el teatro portugués del siglo XVIII. 2. Entremeses y comedias del teatro de cordel. O Galego Lorpa y O Galego Surdo. 3. Otros entremeses y comedias del teatro de cordel. 4. Conclusiones. 5. Obras citadas. 6. Referencias bibliográficas.

Cómo citar: Carrasco González, J. M. (2020): “La lengua gallega en el teatro de cordel portugués: estudio lingüístico”, en Madrygal. Revista de Estudios Gallegos 23 Núm. Especial, pp. 61-78.

1 Trabajo realizado en el ámbito del proyecto "Frontera hispano-portuguesa:personas, pueblos y palabras" (FRONTESPO-3P), financiado por FEDER/Ministerio de Ciencia, Innovación y Universidades-AgenciaEstatal de Innovación, periodo 2019-2022 (ref. RTI2018-095899-B-I0).

2 Universidad de Extremadura. Departamento de Lenguas Modernas y Literaturas Comparadas.

Correo-e: : jcarrasc@unex.es; http://orcid.org/0000-0002-2097-4553. 


\section{La figura del gallego en el teatro portu- gués del siglo XVIII}

Como se aprecia en las fechas en que se publican las obras objeto de análisis, la figura del gallego es característica de una producción teatral aparecida en Portugal en la segunda mitad del siglo XVIII, con algunos continuadores de principios del XIX. Aparece sobre todo en comedias y entremeses ${ }^{3}$ pertenecientes al denominado teatro de cordel. Según Stegagno Picchio, en muchas de estas obras se ha sustituido al ratinho de los antiguos autos de Gil Vicente y su escuela por "esse obtuso campónio que baixava a Lisboa em busca de trabalho" (Stegagno Picchio 1969: I, 199).

El teatro de cordel es tratado de forma unitaria desde los Subsidios para a história do teatro português de Sampaio (1920), elaborado a partir de su excelente colección de piezas que posteriormente pasaría a formar parte de la biblioteca del Teatro Nacional D. Maria II. Aunque abundan las comedias y entremeses de carácter jocoso, lo cierto es que el teatro de cordel está constituido por obras de carácter muy heterogéneo y no es posible considerarlo un género dramático sino, como advierte Duarte Ivo Cruz, "uma forma ou fórmula de divulgação, e sobretudo um espírito e época de intensíssima vivência teatral" (Cruz 2001: 104).

De entre todo ese conjunto de piezas interesa en especial una abundante producción de "mogigangas ou entremezes, que ridiculizam sobretudo vários tipos sociais miseravelmente dependentes: o criado, o galego, o peralta, o sacristão, a beata, etc." (Saraiva y Lopes 1982: 658). Pero, a pesar de que la crítica ha adscrito la figura del gallego exclusivamente a este tipo de obras impresas y vendidas como literatura de cordel, lo cierto es que también aparece en entremeses y comedias de autores reconocidos que reunieron sus obras en ediciones cuidadas y dirigidas a un lector culto. Este es el caso de Manuel de Figueiredo, en cuyo teatro tanto la figura del gallego como su expresión lingüística reciben un tratamiento más respetuoso y menos hiperbólico que en las obras del llamado teatro de cordel (v. Carrasco 2020).

La figura del gallego en el teatro portugués retrata al emigrante gallego que durante el siglo XVIII fue muy numeroso en tierras lusas, sobre todo en la ciudad de Lisboa. Se ofrecían para multitud de oficios humildes, muchas veces para pequeños encargos que los vecinos les hacían eventualmente, como acompañar a enfermos y personas mayores, hacer recados, cargar bultos, facilitar el acceso a los carruajes, etc. En especial destaca el oficio de aguador en la capital portuguesa, prácticamente monopolizado por gallegos durante décadas. También trabajaban como criados en muchas casas acomodadas. La mayoría de ellos eran emigrantes de temporada (iban y volvían cada año) o solo permanecían en Portugal el tiempo suficiente para reunir un dinero que les permitiese comprar unas tierras o buscar mejor acomodo en su lugar de origen. Otros acabaron por quedarse, siendo muy características de esta época las fondas y casas de comida fundadas por gallegos.

Una descripción bastante completa del emigrante gallego en el siglo XVIII, en diferentes perspectivas, puede verse en Leira (2008). La prosperidad económica de Portugal, especialmente visible en Lisboa, gracias al oro de Brasil y al comercio de sus colonias, atrajo a muchos extranjeros y particularmente a esta multitud de gallegos que a finales del siglo XVIII se calcula en cuarenta mil solo en la capital, un diez por ciento de los cuales, según Coelho (2018: 192), eran aguadores. A pesar del trato humillante que reciben en el teatro, se hicieron indispensables en la sociedad de la época. Como advierte Castelo Branco Chaves en su edición de Viagem a Portugal de Carl Israel Ruders, hasta tal punto era así que en 1801, cuando las tropas españolas entran en Portugal en el transcurso de la llamada Guerra de las Naranjas, fueron expulsados todos los españoles del país salvo los gallegos, pues no era posible sustituirlos por otros trabajadores: "Quando, em 1801, foi promulgado o édito a que Ruders se refere [la expulsión de los españoles del territorio portugués], Pina Manique representou ao governo para que tal medida não abrangesse os galegos, pois de contrário não haveria quem os substituísse, em número suficiente" (Ruders 2002: I, 365, n. 5).

El teatro de Manuel de Figueiredo, así como los textos que su hermano Francisco Coelho de Figueiredo incorpora a la edición de sus obras completas, ofrecen una descripción mucho más realista y amable del emigrante gallego en 
Lisboa que el teatro de cordel, siendo incluso muchas veces encomiástica y agradecida, como se puede ver en el estudio de Carrasco (2020). En este mismo trabajo se ofrece una descripción del lenguaje de estos personajes, cuyas características son las siguientes: a) ausencia del diptongo nasal final [ãw̃] típico del portugués; b) pronunciación relajada de las vocales nasales; c) betacismo; d) pronunciación de la consonante nasal final; y e) diptongo oi en lugar de $u i$ (caso de moito). Todos estos rasgos son ciertamente característicos del gallego y no muestran una distorsión o exageración con fines caricaturescos. Además los gallegos salpican su lengua con abundantes castellanismos de diverso tipo que, en general, no eran entonces (como no lo son ahora) propios del gallego coloquial, por lo que muy probablemente se explican por un empeño de los gallegos de la época en adornar su locución (tenida en poca consideración por los portugueses) con formas propias de otra lengua de prestigio, el castellano, con las que ganarse mayor respeto.

La profesora Fernanda Miranda Menéndez llevó a cabo un breve estudio de la lengua hablada por los gallegos en el teatro de cordel a partir, fundamentalmente, de los datos recogidos en el entremés $O$ Velho Peralta. Identifica en estos personajes, sin duda, los rasgos fonéticos que caracterizan al gallego frente al portugués: "a não existência da sibilante sonora $/ z /$, da fricativa palatal sonora $/ 3 /$, da fricativa labiodental sonora $/ \mathrm{v} /$ e dos ditongos nasais" (Menéndez 1994: 451). Sin embargo, advierte que estos rasgos son presentados sin ningún rigor lingüístico, donde destaca "o uso da fricativa palatal surda / $/ /$ a substituir uma série de fonemas sibilantes portugueses, surdos e sonoros" que constituye una distorsión de la pronunciación real de un gallego (conhexia por 'conhecia', dixendo por 'dizendo', exa por 'essa', etc.), al tiempo que los otros rasgos fonéticos "também se verificam nos dialectos do Norte de Portugal" (Ibid: 451-452). Estas características, junto con otras explicadas de forma menos convincente ${ }^{4}$, le llevan a la conclusión de que los autores del teatro de cordel no conocían verdaderamente el gallego por falta de gramáticas y diccionarios en aquella época, que se dejaban llevar sobre todo por rasgos norteños que tradicionalmente se han considerado en Portugal agallegados y, en definitiva, que no es una lengua real, sino "uma estilização do galego, utilizado quer com fins lúdicos, quer como crítica social" (Ibid.: 453).

\section{Entremeses y comedias del teatro de cor- del. O Galego Lorpa y O Galego Surdo}

Para la recopilación de todos los entremeses y comedias del llamado teatro de cordel donde aparece la figura tradicional del gallego, se han analizado los que se conservan en la colección de la Biblioteca/Archivo del Teatro Nacional D. Maria II de Lisboa, la colección más rica de este tipo de teatro que se conserva en Portugal (http://www.tndm.pt/pt/biblioteca-arquivo/). De entre las 912 obras allí conservadas, en la base de datos que se pone a disposición de los interesados figuran 777 piezas, si bien muchas de ellas son obras repetidas en impresiones diferentes. En los casos de varias ediciones, he optado por la más antigua cuando aparecen fechadas. Entre todas ellas, he encontrado 14 diferentes en las que se reproduce el habla peculiar de los gallegos fechadas entre 1773 y 1819 , doce entremeses de acto único y dos comedias de tres actos (O Negociante Imprudente y Assembleia).

Solo dos obras refieren en el título la figura del gallego, lo que hace de esta su principal reclamo, y en ambas se lleva a cabo una ridiculización extrema del personaje: $O$ Galego Lorpa y $O$ Galego Surdo. Son las obras paradigmáticas del teatro portugués de Setecientos con gallegos, por lo que iniciaremos por ellas nuestro análisis.

El Novo entremez intitulado Gallego Lorpa, e os Tolineiros (1808) ofrece una caracterización exagerada y artificial de la forma de hablar de los gallegos, pero sin duda los espectadores (y lectores) identificarían fácilmente aquellos rasgos que llamaban la atención de los portugueses de la época cuando los oían hablar por las calles de Lisboa. Alonso, que así se llama el criado en esta obra, posee además una lengua muy castellanizada, hasta el punto de que algunas frases son más castellanas que portuguesas: "ora quiem la quiere viem fresca, fresquinha, quien la quiere vien fresca"; "ella estava mamando em la madre que la engendrou, e mais oitra ermanita"; "Ora boime a

4 Fernanda Miranda Menéndez considera erróneamente que el gallego, al contrario que el portugués, presenta una colocación preferentemente proclítica de los pronombres átonos y, por otro lado, confunde determinados casos de $a$ protética con el uso de la preposición $a$ (v. Carrasco 2020: n. 6). 
bestir las xiroilhas para ver que taes mi quiedaõ"; "Hei berdade, oigamos, oigamos"; "io que jugo la cavria xiega como ninguno: todos los Domingos la jogaba"; etc.

El castellano de Alonso contiene numerosos errores que no consentiría un buen conocedor del idioma y de sus letras como era Manuel de Figueiredo. Sin embargo, al público iletrado portugués complacería perfectamente y su mezcla con la fonética más o menos agallegada produciría el efecto de ridícula jerigonza que se buscaba. Es posible encontrar diptongaciones inexistentes, por ultracorrección: biengo por 'vengo', guesta dellas por 'gusta de ellas', quiedaõ por 'quedan', fuendo por 'fondo', miétte por 'mete', dientro por 'dentro'. Hay, por el contrario, un caso de ausencia de diptongación en jugo por 'juego', si no es mera errata ${ }^{5}$. No faltan confusiones en el uso de posesivos, artículos y pronombres de complemento directo: mios companheiros; lo ferrogo, mezcla de 'o ferrolho' y 'el cerrojo'; lhos Xenhores, 'los señores'; se lhos beijo, mezcla de 'si los veo' y 'se os vejo'; lo mei dinheiro. En el caso de tanvien io a la quiero parece que repite, quizás por errata o confusión del impresor, el pronombre en portugués y castellano, si no es un caso de $a$ protética en el artículo, pues ejemplos tan extraños como este de $a$ protética no faltan en otras obras. Como hemos visto en el caso de Xenhores, pero también en otros casos como el pronombre elhas, no se respeta la ortografía del español.

En cuanto a los rasgos propios del gallego, destaca la pronunciación como [J], con grafema $<\mathrm{x}>$, de todas las sibilantes: predorsodentales y palatales, sordas y sonoras. Algunos ejemplos: boxas mixeas por 'vossas mercês', boxa merxe por 'vossa mercê', xeu por 'seu', Xenhor, dexinquieto por 'desinquieto', axim por 'assim', axima por 'acima', Praxa por 'Praça', xá por 'já', enxerga, peixe, faxer por 'fazer', prexixo por 'preciso', duxentos por 'duzentos', xogabã̃ por 'jogavam', etc. Es evidente que refleja el ensordecimiento de las sibilantes en gallego moderno y la pronunciación como [J] de la única sibilante palatal, un rasgo innegable que diferencia este idioma del portugués y que sin duda llamaría la atención de los lisboetas de la época ${ }^{6}$, pero hay, como en los castellanismos, un exceso en la representación de este rasgo con fines humorísticos. El exceso traiciona al autor, que lleva a poner en boca de Alonso este mismo fonema en lugar de la africada [t $\mathrm{f}]$ : muxas y muxos en lugar de las formas españolas 'muchas' y 'muchos', y xamaõ en lugar del portugués 'chamam'. Resulta muy significativo no solo porque es un rasgo ausente del gallego en todas sus variedades, sino porque la fricativización de la africada, propia del portugués de nuestros días, se generalizó en la norma de Portugal precisamente en la época en que se escribe este entremés (véase Teyssier 1982: 53-54). Parece razonable pensar que esta pronunciación, típicamente portuguesa, aún era un rasgo marcado en ese momento y, aunque muy característico de Lisboa, debería sonar vulgar. Finalmente, un último ejemplo pone en boca del criado gallego la confusión entre fricativa y africada, en este caso haciendo africada una fricativa: Cazal de vaicho por 'Casal de Baixo'.

Otro rasgo constante es el betacismo: boxas mixeas por 'vossas mercês', bim, de bagar, Bigos por 'Vigo', xerbir por 'servir', bendia, andaba, xerbido por 'servido', bá, birei, bai, bestir, biere, probeito, berdade, jogaba, beijã̃ por 'vejam', Bamos, Boxê por 'você', bio por 'viu', ber, habia, etc. Al mismo tiempo, aparece la labiodental en lugar de la bilabial, quizás reflejando una posible hipercorrección de los gallegos, pero sin duda aumentando la extrañeza del habla de este personaje: voca, Vento por 'Bento', el ya citado Cazal de vaicho, varro, vuscar, vradar, quivravaõ por 'quebravam', vom, cavrinha, vorrego, votei por 'botei', vra$d a$, voa por 'boa', etc.

Al contrario que en otras obras, la ausencia del diptongo nasal final $[\tilde{\alpha} \tilde{w}]$ no se representa sistemáticamente, sino solo en algunas palabras muy características del gallego que se repiten en muchas obras del teatro de cordel: num y nun (por 'não'), som y xom (por 'sou'), xom y Xon (por 'são', presente de ser). La forma num, que revela la relajación de las vocales

\footnotetext{
Hay varias erratas en formas castellanas: ninguro por 'ninguno', cuntos por 'cuentos', quié por 'quién'.

6 Casos de ensordecimiento de las sibilantes, palatales y no palatales, se documentan en el gallego antiguo: "os procesos de desafricación e desonorización de sibilantes teñen raíces seguras no galego medieval" (Mariño Paz 2017: 249). Sin embargo, los primeros testimonios directos donde se describe este fenómeno en gallego solo se producen a mediados del siglo XVIII, en el Catálogo de voces y frases de la lengua gallega del padre Sarmiento (Ibid.: 485488), en época casi coincidente con las primeras muestras del gallego en el teatro portugués.
} 
átonas nasales en gallego ${ }^{7}$, viene acompañada en esta ocasión de otro ejemplo: im por 'em'. Por otro lado, las formas con $<$ n $>$ final nun (que solo aparece una vez) y Xon parecen representar la pronunciación de la consonante nasal en gallego, al contrario de lo que ocurre con las vocales nasales portuguesas en posición final. Es posible que la sustitución de la grafía $<$ n $>$ final por $<$ m $>$ en el resto de formas se hiciese por una mala lectura del original manuscrito por parte de la imprenta (una lectio facilior). En cualquier caso, he comprobado que otro ejemplar de esta obra que se conserva en la Biblioteca del Teatro Nacional D. Maria II, fechada en 1845, también utiliza sistemáticamente $<\mathrm{m}>$ final, lo que parece indicar que es mera copia de impresiones previas (v. Novo entremez intitulado Gallego Lorpa, e os Tolineiros, 1845). Además, en otros textos del teatro de cordel también aparecen casos de $<\mathrm{n}>\mathrm{y}$ $<\mathrm{m}>$ en posición final indistintamente ${ }^{8}$.

He dejado aparte el caso del verbo haver en hande estar, porque en la grafía de la época aparece unido a la preposición y, en consecuencia, no exige la grafía <ão $>$ (también $<$ aõ $>$ en la época) o incluso $<$ m $>$ final.

Quizás puedan interpretarse como la pronunciación típicamente gallega de los hiatos desaparecidos del portugués moderno ( $\mathrm{v}$. Teyssier 1982: 40-45) la aparición de formas, por otro lado no gallegas, como boxas mixeas, xua mirxêa, xua merxêa, xuas mercêas, y Boxa merxêa, correspondientes a 'vossas mercês', 'sua mercê', 'suas mercês' y 'vossa mercê'.

Llama la atención el uso en boca de Alonso de la forma disimilada del diptongo oi (en lugar de $o u$ ), puesto que precisamente es un fenómeno que caracteriza al portugués moderno frente al gallego': cousa (gall.) / coisa (port.), touro (gall.) / toiro (port.), dous (gall.) / dois (port.), etc. Sin embargo, esta disimilación aún sería considerada vulgar, inaceptable en el buen portugués de la corte, por lo que sirve más para acentuar la rusticidad del lenguaje que los rasgos estrictamente gallegos de este personaje. Algunos ejemplos: oitra, coisa, oitros, nestroito, oitro, coixixima por 'coisíssima', etc. Se acentúa su carácter vulgar por la aparición precisamente de formas que acabaron por no ser aceptadas en el estándar portugués, caso del indefinido oitro. Y aún más en el caso de mei por "meu", pues la disimilación del diptongo eu tuvo históricamente menor extensión y debía ser ya muy raro oírla en Lisboa en esta época, según se deduce de los poquísimos testimonios existentes, dándose la circunstancia de que actualmente es una forma desaparecida de Portugal pero viva aún en las hablas de Jálama (v. Carrasco 2010: 8-12).

Relacionado con la disimilación de ou, y acentuando la confusión de la lengua del personaje, hay un caso de sustitución de oi por ou: en la palabra apous, en lugar de "pois", forma con $a$ protética que, también en otros casos, sirve para caracterizar la lengua de los gallegos. Puede que sea una ultracorrección de formas con oi porque aún en la época se consideraban vulgares o bien una representación del vulgarismo pos. Sea como fuere, igual que en la confusión de $b / v$, también en este fenómeno las soluciones se barajan de forma arbitraria distorsionando caricaturescamente la expresión del personaje.

7 El adverbio gallego "non", cuando se pronuncia de forma átona, relaja la vocal en la misma medida que cualquier vocal átona oral. Esto no ocurre en portugués, en la pronunciación común de Portugal, pues las vocales nasales en posición átona mantienen su pronunciación plena y no alteran nunca su timbre: "por efecto de la nasalización las vocales abiertas se han hecho cerradas y las relajadas y neutras recobran su timbre, cerrándose también" (Vázquez Cuesta y Luz 1971: I, 334). Esa pronunciación relajada de la vocal, en una partícula tan frecuente, debía resultar especialmente chocante a oídos de los portugueses, que la representaban como num o nun, aunque no es normal en la pronunciación gallega elevar tanto la vocal. Solo localmente, como en A Guarda, es posible encontrar una pronunciación sistemática con [u] (véase el Arquivo do Galego Oral, http://ilg.usc.es/ago/).

8 La pérdida de la nasalidad vocálica en gallego, y más concretamente la pérdida de nasalidad ante consonante nasal trabante (aunque con más propiedad habría que decir que la vocal mantiene la resonancia nasal al mismo tiempo que se pronuncia la consonante nasal) es tema controvertido. Para los especialistas en diacronía portuguesa, el portugués moderno mantiene una nasalidad en esa posición que ya existía en el galaico-portugués arcaico y, en consecuencia, debería ser común al habla de Galicia y Portugal que aparece recogida en los primeros textos escritos de esta lengua. Sin embargo, algunos lingüistas gallegos no están de acuerdo con que "no galego medieval se formasen vogais nasais fóra dos contextos sinalados en que houbo nasalización vocálica anticipatoria con eliminación de /-n-/ intervocálico ou nasalización dilatoria" (Mariño Paz 2017: 248). En todo caso, la desnasalización completa del gallego no es posible constatarla en la documentación escrita, quizás por su carácter conservador, hasta bien entrado el siglo XVI (Ibid.: 269-271).

9 La disimilación de oi por ou está registrada en la documentación gallega desde época medieval, pero siempre de forma muy minoritaria (v. Mariño Paz 2017: 303). 
Muy interesante es el fenómeno que encontramos en las formas rabios por 'rabos', encommendiou 'encomendou' y tampios por 'tampos'. En el gallego moderno se han adoptado muchas soluciones cultas o semicultas en palabras que en portugués no mantienen la yod ${ }^{10}$, si bien en nuestros días hay una corriente importante que pretende restituir la forma antigua de algunos términos como Galiza o grazas ${ }^{11}$. En cualquier caso, a un portugués de la época de este texto que escuchase hablar gallego le llamarían sin duda la atención esas formas con yod, aunque, en este caso, el autor la ha introducido en palabras que nunca la tuvieron acentuando la incorrección lingüística del personaje.

Otro rasgo propio del gallego, frente al portugués, que aparece en la obra es la forma hai del verbo haber, que en portugués no existe, pues solo se usa há. Sin embargo, como en el caso anterior, la forma hai aparece en casos donde el gallego usaría exclusivamente $h a ́$, pues se trata de la perífrasis de haver de + infintivo (gallego 'haber de'): que me haide pagar os tres mil e duxentos, Boxê hei que haide pagar, etc. Como ocurre también en otros rasgos, de una forma realmente existente (aunque mal usada) se pasa a otra que nunca existió en gallego, que es ei en lugar de é (del verbo ser), repartida a lo largo de todo el texto.

La pronunciación portuguesa moderna, ya desde el período clásico, produce el fenómeno de generar una yod ante consonante palatal o asimilar la yod de un diptongo ante estas consonantes ${ }^{12}$. Algunos autores la adoptaron como opción culta ${ }^{13}$. El texto recoge en boca del gallego este fenómeno: beijo por 'vejo', beijã̃ por 'vejam' y boixê por 'você'.

Por último, es importante advertir que el texto reproduce claros galleguismos como som (presente del verbo ser, gallego 'son'), num (adverbio de negación, gallego 'non') y fum (indefinido del verbo ir, gallego 'fun'). Quizás se percibiese en la época también como un galleguismo antonxes (gallego 'entonces, entón'). Es cierto que la Real Academia Galega considera que entonces es una forma incorrecta y solo debe usarse entón, pero no es menos cierto que entonces era y es en la actualidad una palabra de uso normal en gallego, del mismo modo que también fue de uso en el portugués antiguo ${ }^{14}$. El autor del entremés no solo reproduce esta palabra por haberla oído de los trabajadores gallegos, sino porque además debía parecer rústica y anticuada a oídos de los portugueses.

O Galego Surdo es un entremés del que la Biblioteca del Teatro Nacional D. Maria II conserva un ejemplar (Drama, O Galego Surdo, 1773). En este caso el personaje gallego no es un criado, sino un rico heredero venido de Galicia para casar con la hija de su primo o de su tío, porque de las dos formas aparece, quizás porque se supone que es el hijo de un primo del padre de la muchacha casadera. Habla un portugués agallegado con mezcla de castellano, incluso respetando la ortografía española: "Mas á Señor Tio, y a cal das caxopas he a Señora Prima?". Hablando de esta manera, sordo y acompañado de una gaita, la aparición en escena de este personaje llamado Balthezar pretendía provocar las carcajadas del público. Que una joven

10 El gallego hablado en el teatro portugués adelanta algunos años la datación de esta característica del gallego moderno. Según Ramón Mariño, al entrar en el siglo XIX, por influencia del castellano, se produce una "preferencia polos sufixos e terminacións -ancia, -encia, -(i)cia e -(i)cio no canto de -anza, -enza, -(i)za e -(i)zo" (Mariño Paz 2003: 285).

11 La Real Academia Galega, en su última edición de las Normas ortográficas e morfolóxicas do idioma galego, se refiere específicamente a estos sufijos (véase Real Academia Galega 2012: 53-55). En alusión a esta moderna corriente que recupera las formas medievales, advierte: "Entre estas palabras está Galicia, voz lexítima galega, denominación oficial do país e maioritaria na expresión oral e escrita moderna. Galiza é tamén unha forma lexitimamente galega, amplamente documentada na época medieval, que foi recuperada no galego contemporáneo" (Ibid.: 54).

12 Las pronunciaciones de tipo caxa o pexe se consideran meras variantes o realizaciones espontáneas de la pronunciación portuguesa estándar de nuestros días (v. Barbosa 1994: 110-111). Si a esto le sumamos el hecho de que cualquier vocal tónica ante palatal heterosilábica pueda pronunciarse con yod hace que, en el mismo contexto fonético, diptongos o vocales acaben por identificarse como fonema vocálico + yod "quer se escreva $i$ quer não" (Ibid.: 171).

13 Caso de D. Francisco Manuel de Melo: "deixando ao Noroeste o temeroso baxo dito Sorlingues: Ilhas baxas somidas das ondas" (1660: 404). En O Galego Surdo, que será analizado a continuación, hay un ejemplo muy ilustrativo, pues aparecen dos formas juntas con y sin yod, en boca de un personaje portugués y en las acotaciones del autor: troxa y troixa (Drama, O Galego Surdo, 1773: 12).

14 Según el Dicionário Houaiss, el adverbio entonces (documentado ya en el siglo XIV), deriva de entonce (que también se documenta en portugués desde la Edad Media) y es de uso arcaico e informal (Houaiss, Villar y Franco 2004: s.v.). 
lisboeta debía casarse con un gallego ("Com hum rustico Galego [...]?") era una situación que podía parecer ridícula y vergonzante, por lo que la criada de la joven le responde con esta afirmación ofensiva: "Coitadinha! Com hum Galego! E o pobre tal vez se sugeite á carga do Matrimonio por estar costumado a fretes".

El castellano de Balthezar presenta, como el de Alonso, numerosas irregularidades que acentúan el efecto cómico. Por ejemplo, vulgarismos (An que por 'Aunque', pôs y apôs por 'pues'), errores en artículos y posesivos (uno bilhancico, mia terra, mio saio), diptongaciones inexistentes (benga enbuera por 'venga en buena hora', portugués 'venha embora'), etc.

La distorsión de los rasgos castellanos y gallegos en la lengua de Balthezar es mucho menor que en la de Alonso. Quizás lo más distante de la realidad sea la confusión de vocales en algunas palabras. Puede que el efecto parta de la alteración de átonas, común en gallego y portugués (apuzento, racado por 'recado', bistidura por 'vestidura', bardade por 'verdade'), pero no en casos como tombin y tomben por 'também' o camida por 'comida', que quizás sirvan para acentuar cómicamente la menor relajación de las pretónicas en gallego que en portugués. De esta alteración de las vocales átonas, el texto pasa a la alteración de las tónicas en soluciones de todo punto inventadas: assanto por 'assento', tume por 'tome', estuba por 'estava', ladruns por 'ladrões' (gallego 'ladróns').

No considero entre los casos anteriores el de la forma nun (por 'não', gallego 'non'), muy abundante en todo el texto, pues su uso está atestiguado en gallego, como ya se vio. En esta forma se constata la no existencia del diptongo nasal final en gallego y la pronunciación de la consonante nasal en posición final, por lo que esta aparece reproducida gráficamente $\operatorname{con}<\mathrm{n}>$. Sin diptongo nasal aparecen también: consolaçon, pon-se, Tan pouco, ladruns y coraçon. A estas hay que añadir otras formas con $<\mathrm{n}>$ final: tombin, tomben, Aben por 'bem' con $a$ protética, ben, Ben, poren, bolen, con, min, conben por 'convém', nin, paraben. En todos los casos responde a la pronunciación de la [ๆ] velar final en gallego. Adviértase que en el caso de nin, igual que en nun, se ha marcado la relajación de las vocales átonas nasales en gallego, que no se produce en portugués.
Otro rasgo característico del gallego recogido abundantemente en el texto es el betacismo: estuba por 'estava', bardade por 'verdade', bilhancico, bai, dubido, bê (del verbo ver), bermelhada, noba, bistidura, bestidura, malbada, trobas, entoaba, noibo, noiba, conben, debe, conbinher (por 'convier'), bocês y bista.

También recoge el texto la pronunciación como palatal sorda [S] de las sibilantes palatales sonoras: xá por 'já', xuro por 'juro', rinxen por 'ringem' (variante aún usada en Brasil en lugar de 'rangem' que podía considerarse más rústica en el Portugal de aquella época), tanxerei por 'tangerei', Axan por 'hajam', lixeiro por 'ligeiro', Sexalhe paraben por 'seja-lhe parabém' y lagramixar-me (derivado humorístico de 'lágrima' con el sufijo -ijar). Solo hay un caso en el que aparece con $<\mathrm{x}>$ una sibilante no palatal: andaxe por 'anda-se'. Al contrario de lo que ocurría en el entremés del Galego Lorpa, en este caso se recoge con bastante fidelidad la pronunciación gallega de estos sonidos.

Por el contrario, y en coincidencia con el Galego Lorpa, también se pone en boca del personaje gallego la pronunciación como fricativa de la antigua africada [t $\mathrm{t}]$ : caxopa por 'cachopa', xamo por 'chamo' y xamo-me por 'chamo-me'. Se trata de una pronunciación inexistente en gallego que empieza a documentarse en portugués en el siglo XVII y que Teyssier (1982, 54-55) considera que ya era aceptada en el habla cortesana a mediados del siglo XVIII. Aunque fuese una pronunciación popular en Lisboa y toda su provincia, es posible que no dejase de estar marcada como vulgarismo o coloquialismo hasta fecha más tardía, pues así lo sugiere el tratamiento que recibe este fenómeno en los textos aquí estudiados.

Una característica que no ha aparecido hasta ahora es la reducción del diptongo [wa] > [a] en [kwa] y [gwa]. Es solución presente ya en el galaico-portugués arcaico, aunque no sistemática. El gallego conserva la solución sin wau en las palabras de uso tradicional, mientras que el portugués ha restituido en general la semiconsonante por influencia culta latinizante ${ }^{15}$. Estos son los casos que se encuentran en el texto: cal por 'qual', cartos por 'quartos' y canto por 'quanto' (en la expresión canto que, que se usa con el sentido de logo que). 
Un último rasgo que caracteriza el habla de Balthezar es la confusión de diptongos. Ya se vio que en el Galego Lorpa se atribuía a los gallegos las disimilaciones de oi por ou y otros fenómenos semejantes. Para un portugués del siglo XVIII la lengua de los gallegos producía alguna extrañeza en cuanto al tratamiento de los diptongos, con formas como oi en lugar de ui o u (moito y coitelo en lugar de 'muito' y 'cutelo'), pero en esta época además se vivía en el portugués una conservación de los diptongos tradicionales ou y ei en la lengua culta y escrita, al mismo tiempo que se generalizaban en la expresión popular y coloquial las asimilaciones en [o] y [e] o las disimilaciones en [oj] y [aj], además de otras formas que no han triunfado en el portugués moderno ${ }^{16}$. Los ejemplos de asimilaciones, disimilaciones y confusiones de diptongos que encontramos en este entremés no responden a la pronunciación real de un gallego, sino que traslada a este formas vulgares, algunas caricaturescas, que para un espectador de la época debían sonar muy rústicas, si bien se trata de formas sueltas y no de un rasgo generalizado en la lengua de Balthezar: soiber por 'souber', oibir por 'ouvir', gauta por 'gaita', cudará por 'cuidará', oitra por 'outra' y sôs por 'sois'.

Finalmente, hay que referir algunos claros galleguismos que aparecen en el entremés: ninguã por 'nenhuma' (gallego 'ningunha'), estón por 'estou' (formación llevada a cabo siguiendo el modelo del gallego 'son', frente al portugués 'sou'), entonces (forma que, como ya se ha señalado, es de uso en gallego aunque se considere, quizás erróneamente, un castellanismo), baya por 'vá' y a y alma por 'a alma' ${ }^{17}$.

\section{Otros entremeses y comedias del teatro de cordel}

En el resto de entremeses o comedias del teatro portugués de la época, el personaje del gallego tiene una presencia mucho más discreta. En Novo entremez dos Desprezos de hum Filho Peralta a Seu Pai, ou Sophismas, com que Enganou a Sua Creada (1774), hay un criado gallego que se expresa de forma bastante estereotipada mediante rasgos que se han analizado ya en los textos anteriores, pero en este caso sin interferencia o mezcla del castellano:

1. Pronunciación de la prepalatal fricativa sorda extendida a los casos de sibilante no palatal: parexeu; boxe, boxê y Boxê por 'você', xe num por 'senão'; nexa por 'nessa'; xinhor; xã̃ por 'são' (del verbo 'ser'); xua y xuas; dixexe por 'dissesse' y dixe por 'disse'; xe; parexem-se; Axim y axim por 'assim'; impoxible; tibexe por 'tivesse'; y enxine. En el caso de dixexe e dixe hay coincidencia con la pronunciación del gallego dixese y dixen, pero no es posible deducir si el autor buscaba reproducir el tema de perfecto gallego o repetir la pronunciación palatalizada de la sibilante predorsodental.

2. Otro rasgo bien representado es el betacismo: boxê, boxê y Boxê; oibe por 'ouve'; bai-me, bai, bi y tibexe. Y al mismo tiempo aparecen, por ultracorrección, casos de [v] por [b]: varvas, cavra, taõvem, vurra, voas, ovras y vusque.

3. También se recogen algunos ejemplos de la confusión de diptongos: oibe por 'ouve' y la conjunción con a protética Apous (3) y apous por 'pois'.

4. Se usa sistemáticamente num, Num y se num (por 'senão'). Sin embargo, no hay ningún otro caso en que no se respete el diptongo nasal final del portugués.

5. Aparece un único ejemplo de relajación de las vocales átonas, en este caso pretónica: xinhor.

6. Si no es errata, la forma Angustas por 'Angústias' es una reinterpretación errónea del -ia final en gallego.

7. Dos galleguismos interesantes se documentan en este texto: el sufijo -ble que encontramos en impoxible y el uso de coma comparativo: coma hum Preto.

El Entremez intitulado: O Velho Peralta (1776) contiene el personaje de un criado gallego que interviene de forma repetida en la obra. En este caso incluye numerosos castellanismos que

16 Para los diptongos, puede verse el estudio ya clásico de Cintra (1983).

17 Este fenómeno también está presente en Portugal. El portugués "manifesta uma forte tendência para a eliminação dos hiatos, seja pela não realização de uma vogal (porto amigo pronunciado [... tạ ...]) ou, no Centro e Norte, pela intercalação de um som de transição, dito iod (a água pronunciado [ạią...]), seja pela crase das duas vogais colocadas em hiato [...]" (Barbosa 1994: 113). 
salpican su portugués agallegado: galhégo, tengo, mas (por 'mais'), Boime (por 'vou-me'), boi (por 'vou'), cozas y bien. Adviértase que la forma galhégo o 'gallego' había sido adoptada por los gallegohablantes, de modo que puede considerarse también un galleguismo. En cuanto al resto de rasgos propios del habla del criado, es posible constatar los siguientes:

1. Pronunciación de las sibilantes como [C], en la mayoría de los casos en lugar de sibilantes no palatales: Xanhor y xanhor (por 'senhor'), xatisfeito, xerbir, Xerbindo, xirbo, xerbillo, a xerbir (por 'servir' con $a$ protética), ixo (por 'isso'), xua, xalto, Xim, xen (por 'sem'), confexo, xei, xargento, dixendo, dixer, Dixe-me ${ }^{18}$, xeo (por 'seu') y moxoila. Hay dos únicos casos en que [S] sustituye la sibilante palatal sonora, como realmente corresponde al gallego: oxeto (por 'objeto') y prodixo (por 'prodígio'). Al mismo tiempo, hay dos casos de palatalización de la sibilante no palatal que quizás responda a la dificultad del gallego en reproducir la predorsodental sonora que no existe en su lengua: cojinha (por 'cozinha') y mugico ( por 'músico').

2. El betacismo es abundante en el texto: xerbir, Xerbindo, xirbo, xerbillo, a xerbir (con $a$ protética), xabos (por 'chavos, ochavos'), Binte, Boime, boi, vida, atrebo, bisto, bi, Bai y belho. No hay ultracorrección de $[\mathrm{v}]$ por $[\mathrm{b}]$.

3. La sustitución de $[\mathrm{t}]$ ] por $[\mathrm{J}]$ también se señala en el habla del gallego: marxo, paxola, muxila (por 'mochila'), xabos y caxopa.

4. Aparece recogida la pronunciación de la nasal final en tres ocasiones: regalan, xen (por 'sem') y an (por 'em').

5. Además del adverbio num y Num, encontramos alteración de las vocales átonas en Xanhor, muxila, an y Antonces.

6. La confusión de diptongos aparece en tres ejemplos: oitro, xeo (por 'seu') y creada. En los casos de xeo y creada se aprecia la pronunciación de hiatos propia del gallego y no del portugués ${ }^{19}$.

7. La confusión de -ia, -io finales aparece en terria, estudio (por 'estudo') y prodixo.

8. Otro rasgo gallego que recoge el texto es la elisión de wau en [kwa]: cartos y canto (por 'quanto').

9. Algunos vulgarismos también son utilizados por el personaje gallego, como en estos casos de metátesis de [ $\mathrm{c}]$ : protento y pertende ${ }^{20}$.

10. Son muy abundantes en este entremés los casos de a protética: a xerbir ('servir'), $E$ a por ixo me despeço (por ' $\mathrm{E}$ por isso me despeço'), De a trabalhar na cojinha (por 'De trabalhar na cozinha'), aperguntei-lhe, arresponde-me, etc.

11. Como galleguismos podemos considerar el uso de medio en lugar de 'meio' (en dous mezes e medio), aunque también podría considerarse castellanismo; a iagua (común con el portugués regional); entonces, Entonces y Antonces (que también pueden considerarse vulgarismos o formas rústicas); son por 'são' (del verbo 'ser') y mui por 'muito' (también arcaico o rústico para un portugués del siglo XVIII). La referencia a monedas españolas de la época, naturalmente, no se puede considerar galleguismo o castellanismo, rasgos fonéticos aparte: xabos, reales y cartos por 'ochavos', 'reales'y 'cuartos'.

12. También se puede considerar galleguismo (por influencia del castellano) el uso de la preposición en las perífrasis con el verbo ir (boi a xerbillo), pero es un uso posible (aunque infrecuente) en el portugués moderno.

En el entremés Os Destemperos de um Bazófia (C., 1779) asistimos a una brevísima intervención de un gallego que entrega una carta. El único rasgo diferencial que contienen sus palabras es el betacismo de binha, imperfecto del verbo vir.

18 Sobre el pretérito de dizer en gallego, véase lo que se comentó en el entremés anterior.

19 No es propio del gallego la alteración de diptongos decrecientes (caso de $x e o$ por 'seu'), pero sí la pronunciación de diptongos crecientes como hiatos, como en creada, ya desde época medieval (v. Mariño Paz 2017: 282).

20 "A metátese, e en concreto a metátese de / $\mathrm{f}$, é un dos fenómenos de alteración do consonantismo máis comúns na oralidade galega popular de todos os tempos" (Mariño Paz: 2003: 83). De la misma época que estas obras de teatro son los muy abundantes casos de metátesis de [c] que recoge el padre Sarmiento, como advierte Mariño (Ibid.: 83). 
Nova comedia De hum Engenho Portuguez denominada Assemblea (1781) es una comedia en tres actos en la que participa un criado gallego llamado Pascoal. Su habla contiene algunos castellanismos, algunos meras adaptaciones del portugués, a veces coincidentes con galleguismos, como muxo por 'mucho', caderas por 'cadeiras', terrina por 'terrinha', benhir por 'vir' y media por 'meia'. Otros rasgos que caracterizan el habla del personaje:

1. Betacismo: bentura, bibe, biba, Atabios, bouma por 'vou-ma', bou, boubeme [sic] por 'vou-me', vida, benhão por 'venham', bem por 'vêm', bintens, lebo, bamos, buces por 'vocês', Beja por 'veja', bestido, bes por 'vez', bella, Belho, faltaba, benhir, beo por 'veio', beria y Debagar. No hay casos de hipercorrección de [v] en lugar de [b].

2. Aparece la pronunciación de [J] en lugar de sibilantes no palatales solo en dos casos: escuxo (por 'escuso') y roxela (por 'rosela'). No afecta a las sibilantes palatales.

3. Existe una confusión entre [t]] y [S], que entonces se consideraría vulgarismo: muxo (por 'mucho'), caxopa y, en sentido inverso, puchões (por 'puxões').

4. Alteración en las vocales átonas: declarisse (por 'declare-se'), Antonces, antonces, custado (por 'costado'), Siringoncias (por 'geringonças'), buces (por 'vocês'), melguinhas ('por malguinhas'), premor (por 'primor'). El caso de declarisse, con la átona palatal final pronunciada como [i], nos transporta a otra innovación fonética que se estaba produciendo a finales del siglo XVIII: la [e] átona final pasó a pronunciarse como [i] a principios de aquel siglo, y se transformó en [!] en el habla cortesana en la segunda mitad del XVIII ${ }^{21}$. Cuando se escribe esta pieza, es posible que una pronunciación [i] fuese sentida ya como rústica y por ese motivo la pone en boca del personaje gallego, aunque no sea propia de su lengua. Parecido es el caso de la pronunciación como $[\mathrm{u}]$ de la $o$ átona pretónica (casos de custado y buces), pues también es un fenómeno que se generaliza en portugués a lo largo de la segunda mitad del siglo XVIII ${ }^{22}$. Finalmente, es interesante advertir los casos de alteración en el timbre de la vocal nasal en el caso de antonces, al que tendríamos que añadir los habituales casos de reducción vocálica en Num, num y n'hum [sic] (errata por num).

5. El caso de num muestra la ausencia del diptongo nasal final portugués, que también se observa en benedisson (por 'bendição').

6. En benedisson y en tamen se registra la pronunciación de la consonante nasal final.

7. El tratamiento de los diptongos también en este entremés se utiliza para imprimir mayor rusticidad al habla del gallego. En el caso de beo por 'veio' quizás se pudiera pensar en que el autor representa efectivamente la pronunciación de los hiatos gallegos, pero no es una interpretación segura debido a la ortografía conservadora de la lengua portuguesa en este período. No falta el caso de mei por 'meu'. La forma noute es variante frecuente en textos portugueses, probablemente sentida como rústica y arcaica en la Lisboa de la Ilustración, muy rara en gallego ${ }^{23}$. La reducción del diptongo (si no es errata) en apoquentem es también propia del portugués meridional, inexistente en gallego. Y es también impropia de esta lengua el caso irregular de gauta por 'gaita', que también se encuentra en otros textos. Finalmente, Sua Merceia, sua merceia y Sua Mereceia parecen una reinterpretación portuguesa de la pronunciación de los hiatos en gallego, siguiendo el modelo de maré (port.) / marea (gall.)

8. El tratamiento de los finales -io / -ia en gallego aparece representado caricaturescamente en las formas Sirigoncias y

21 V. Teyssier 1982: 57-60. Paul Teyssier documenta algunos casos probables que le permiten suponer que en el habla lisboeta ya era pronunciada así antes de 1770, pero la primera referencia expresa a esta pronunciación solo aparece en el Maître Portugais de 1799.

22 Según Teyssier (1982: 60-62), hacia 1800 la evolución de [o] > [u] pretónica se habría consumado, pero aún en 1767 el Compendio de Orthographia de Luís do Monte Carmelo condenaba esa pronunciación.

23 "No galego o intercambio en dobre sentido entre os ditongos /' ou/ e /' oi/ (oiro por ouro, noute por noite, etc.) distou moito de alcanzar a extensión que si alcanzou en portugués" (Mariño Paz 2017: 303). Según Ramón Mariño, la presencia en la documentación medieval es escasa y en los dialectos modernos del gallego tiene una presencia muy restringida (v. Fernández Rei 1990: 48-51). 
murrazios (por 'murraços', aumentativo de murros).

9. El personaje Pascoal utiliza en dos ocasiones el verbo gallego 'pescudar' con alteración de la vocal pretónica: poscudalla $\mathrm{y}$ poscudo.

10. Los casos de hai por 'há', media por 'meia', así como los ya vistos de Antonces y antonces pueden ser considerados castellanismos o galleguismos indistintamente. Las formas tamen, tãomem y tamem por 'também', además de ser gallegas, son también vulgarismos o coloquialismos portugueses. La conjugación del verbo 'fazer' con un tema $f a g(u)$ - es propia de algunas variedades del gallego, aunque algunas de las formas presentadas no sean correctas: faga por 'faça', faguerei por 'farei', fagia [sic] por 'fazia' y fagio [sic] por 'faço' ${ }^{24}$. Por otra parte, em trementes (por 'entrementes') es infrecuente en portugués y puede ser considerado un galleguismo de uso.

\section{El Novo Entremez Intitulado Casquilharia por} Força (1781) presenta un criado gallego llamado Marçal que habla sin interferencias del castellano, salvo en la expresión a más con el sentido del español 'además'. En general, Marçal mantiene un portugués con pocas formas vulgares y agallegadas, y las que aparecen no se repiten de forma sistemática. Estos son los casos encontrados:

1. Betacismo: nobidades, dubeda (por 'dúvida'), binher, berdade, cabar, binha (sustantivo), bale (presente de 'valer'), $b a$ (subjuntivo de 'ir').

2. Rasgo repetido es el uso, común en todas las piezas, de num y Num. Otros casos de ausencia de diptongo nasal final: som y son, en ambos casos tercera persona del presente de indicativo del verbo 'ser'.
3. El caso de son revela la pronunciación de la consonante nasal en posición final. En un pasaje de la obra, Marçal se equivoca al repetir una palabra que le dicen y él no conoce: dice fonson en lugar de função. También aquí se documenta la pronunciación gallega de consonante nasal final, en este caso en lugar del diptongo portugués.

4. Además de num, hay otro ejemplo de relajación de vocal nasal átona: intendo (por 'entendo'). Debe considerarse un vulgarismo en una época en que la pronunciación culta lisboeta sustituía la pronunciación tradicional con [ĩ] por [ẽ $]^{25}$.

5. En cuanto a la confusión de diptongos, hay dos casos: Pous y acuidir. En el caso de acuidir, el autor rehace un diptongo donde no existía tomando como modelo ejemplos del tipo gallego 'truita' (o 'troita') frente al portugués 'truta'. En el caso de Pous, más que una sustitución del diptongo oi por ou (las formas portuguesas con disimilación, como coisa o toiro, no se admitían en el portugués culto de la época), podemos ver una reinterpretación del vulgarismo gallego pos (por 'pois'), o bien una confusión de ambos fenómenos ${ }^{26}$.

6. La pronunciación de las sibilantes portuguesas presenta rasgos propios en este personaje. En todos los casos pronuncia la palatal sonora [3] en lugar de [z]: fagendome por 'fazendo-me' y trajer por 'trazer', fenómeno que podemos atribuir, como advertimos en otros textos, a la dificultad de pronunciar [z]. Extiende esa misma pronunciación a un caso de $<\mathrm{ch}>$ : jaleco por 'chaleco'.

7. Otros casos que encontramos son: traiga (por 'traga') ${ }^{27}$ y los ya conocidos de la yod antihiática en aiagua y el adverbio entonses.

24 Las formas que responden al modelo de faguer son difíciles de documentar en esta época. Ramón Mariño solo encuentra un ejemplo del infinitivo faguer en un refrán recogido por Sobreira (2003: 232-233).

25 Según Morais Barbosa, "as pronúncias com [ẽ] inicial, decerto devidas à influência da ortografia, são modernas, enquanto as pronúnicas com [ĩ] são tradicionais” (1994: 189). Para Paul Teyssier, la pronunciación como [ĩ] en el grupo de en + consonante en posición inicial era una tendencia que se comenzó a manifestar en el siglo XVI (1982: 60) y no tiene nada que ver con la evolución de las vocales átonas pretónicas en el portugués moderno.

26 Aunque aún no se admitía en el portugués culto del siglo XVIII, la pronunciación como [o] del diptongo ou ya está documentada desde el siglo XVII (v. Teyssier 1982: 52).

27 También este testimonio resulta valioso para la historia del gallego, pues según Ramón Mariño, "nos textos pregaleguistas que usan exclusiva ou preferentemente traguer [...] obsérvase unha clara tendencia a manter o radical tragen todo o tema de presente, sen substitúlo en ningún caso polo castelán traig-" (2003: 249). También debemos considerar la fuerte interferencia del castellano que, en todas estas obras, se observa en la lengua de los gallegos. 
El Novo entremez das Regateiras Bravas (1786) presenta un criado gallego cuya lengua posee algunos castellanismos: mas por 'mais', mismo, tambien, su merced, Su Mercè, tengo, Gasus! (exclamativa, por 'Jesús'), sangre, gusticia por 'justicia'. Los castellanismos mismo y sangre también son de uso habitual entre los hablantes de gallego moderno. Del resto de rasgos, es posible encontrar los siguientes en el habla del personaje:

1. Betacismo: bi, bós, stubera, bú (por 'vou'), búcè ('você'), Binhera (por 'viera'), brabas, bisto (participio de verbo 'ver').

2. Solo encontramos alteración de sibilantes en el verbo dizer (dixera) y en la 's-' inicial de 'senhor': Chanhor, chanhor y chanhora. No hay, por lo tanto, una sustitución sistemática de las sibilantes portuguesas por [S], por lo que es posible deducir que dixera es una forma propia de la conjugación gallega. Las formas de 'senhor', caricaturescas, muestran la no relajación de la $e$ pretónica (abierta exageradamente en [a]) y quizás una pronunciación apicoalveolar de la $s$, presente en algunas zonas de Galicia y en el norte de Portugal.

3. La pronunciación peculiar de las vocales átonas muestra otros ejemplos además de chanhor/chanhora, entre las que se pueden incluir la referida forma exclamativa $G a$ sus (donde la $<\mathrm{g}>$ parece representar la velar fricativa sorda del castellano o bien una pronunciación defectuosa de ese sonido), minhor (errata por milhor) y la $u$ de sintrumeta ('se entrometa'), así como los casos de relajación de vocales átonas nasales: el adverbio num (también escrito n'un en una ocasión), pundero (por 'pondero') y la $i$ inicial de sintrumeta, un ejemplo más de en + consonante en posición inicial.

4. Como ya hemos visto en otros textos, también aquí la confusión afecta a algunas vocales tónicas: bú por 'vou' y cumpre (por 'compre'). Ninguna de las formas se corresponde con el gallego, que en este caso coincide con el portugués. En bú podemos ver reflejados los problemas de asimilación y disimilación de los diptongos en portugués moderno interpretados erróneamente por un hablante de gallego. En el caso de cumpre, puede haber una confusión por parte del autor, quien conjuga de forma distinta el verbo imitando otras formas verbales gallegas que se distinguen de las portuguesas en la vocal temática. En la confusión de la tónicas también podríamos incluir aquí la forma verbal stum (por 'estou') que comentamos a continuación.

5. El personaje pronuncia siempre el diptongo nasal final, salvo en el caso del adverbio num y de pan (por 'pão'). En este último caso aparece representada la pronunciación de la consonante $n$ en posición final, como también en ten, Quen y el ya citado n'un.

6. Hay que considerar galleguismos la conjugación del verbo 'estar' con vocal temática $u$ en el tema de perfecto (stubera) y del verbo 'vir' con nasal palatal (Binhera). La forma stum por 'estou' parece una reinterpretación errónea del autor de la conjugación gallega como veíamos anteriormente (por ejemplo, al comparar el gallego 'son' y el portugués 'sou'). En el caso de stubera y stum hay una eliminación de la $e$ inicial que hay que relacionar con la evolución de esta vocal en el portugués de la época, aquí recogido probablemente como un vulgarismo para marcar peyorativamente el habla del gallego.

7. Las formas Pos por 'pois' y despos por 'depois' podemos atribuirlas a galleguismos, más que relacionarlas con los problemas de la asimilación y disimilación de los diptongos portugueses, como vimos en otros textos. La expresión exclamativa $\mathrm{Per}$ Xisto parece una deformación eufemística de 'Por Cristo'. Finalmente, munto por 'muito' no es más que un vulgarismo o coloquialismo estrictamente portugués.

En Nova pessa, intitulada O Mizeravel Enganado (1788) interviene un gallego aguador que se caracteriza por no mezclar su lengua con castellanismos. Estos son sus rasgos:

1. Betacismo: Beja (por 'veja'), haber, bazo (presente del verbo 'vazar'), benho, imbergonhou, mizerabel, belho, ver, rezolbe, bá (subjuntivo de 'ir'), mandaba y bou. Hipercorrecciones: varil (por 'barril'), prove y proves (por 'pobre' y 'pobres') y vairro.

2. No aparece la pronunciación [J] de las sibilantes portuguesas, pero sí estas formas del pretérito del verbo dizer: dixe ( $1^{\mathrm{a}}$ persona) y dixo (1788: 6). Hay que considerarlos claros galleguismos, como también entrementes, traigo (por influencia del castellano) y el adverbio num, Num y nom. 
3. Formas sin el diptongo nasal final característico del portugués encontramos en son (por 'são', del verbo 'ser'), envison (de interpretación dudosa) y milhons. A esto hay que añadir el caso ya visto de num/nom.

4. Pronunciación de la consonante nasal en posición final: dizen, quen y ten.

5. Hay un caso de pronunciación como [ĩ] del grupo inicial en + consonante: imbergonhou. No hay ningún otro caso de relajación de la vocal átona nasal, aparte del adverbio num ya referido.

6. Conserva la pronunciación de todos los diptongos portugueses de la época, salvo en un caso de mei por 'meu'. Más que una alteración en la pronunciación de los diptongos hay que considerarlo un vulgarismo rústico. Otros vulgarismos: prove y proves, Quantes (por 'quanto a') y tal vez atolico por 'atolado' (dudoso).

Uno de los personajes del Novo entremez intitulado A Habitaçam da Loucuar [sic] (1790) es un criado gallego llamado Beltrão que interviene poco y lo hace en un portugués bastante correcto. No muestra ninguna interferencia del castellano y los únicos rasgos propios que muestra son el uso del posesivo mei por 'meu', siempre en la expresión 'mei amo', y dos ejemplos de betacismo: nobidades y serbe (presente del verbo 'servir').

En la Comedia nova, intitulada O Negociante Imprudente (1792), un gallego mozo de carga hace una breve intervención sin interferencia del castellano. En ella se encuentran los siguientes rasgos:

1. Betacismo: bossa mercé, bir, lebar, bai, bou, Bamos.

2. Utiliza el adverbio num y Num, así como la conjunción senum por 'senão'. Además de estos casos, no hay irregularidad en la pronunciación de los diptongos nasales del portugués, salvo en la forma verbal sum (por 'sou').

3. Hay una alteración en la vocal tónica tanto en sum (gallego 'son') como en unde (por 'onde').

4. Hay un caso de reducción del diptongo en [gwa]: agardando.

En el Novo entremez intitulado A Correcção das Vaidosas (1819) interviene un criado gallego llamado Braz de rasgos lingüísticos muy acentuados. Incluye numerosos castellanismos: más (por 'mais'), tengo, benhir (por 'vir'), ahora, su mercê, sú mercê, sus mercês, boi (por 'vou'), boi-lhas (por 'vou-lhas'), baia, baia! (exclamativa), baia (por 'vá'), adelante, aquelhas, poner y sangre. En la expresión chegame a guélla a esganar-me, guélla presenta una ultracorrección con diptongo de 'gola'. Aunque no sea una construcción inexistente en portugués, Braz recurre constantemente a la perífrasis del verbo 'ir' con la preposición 'a': boi á texélla, boi a serbir-la, Bou a comer... Otros rasgos encontrados en el habla del gallego:

1. Betacismo: bén (por 'vem'), boi (por 'vou'), bassa (por 'vaza'), baia, baia!, (exclamación), baia (por 'vá'), habia, barrer, Bou, Sílbra (por 'Sílvia'), attabios, a berdadêssa (por 'a verdade'), bal (presente del verbo 'valer'), biba, noiba, Bailla, oubia y bio (por 'viu'). Hay un caso aislado de ultracorrección: vrôa (por 'broa').

2. Las sibilantes en las intervenciones de Braz se ajustan con fidelidad a las sibilantes gallegas, de tal modo que todas las sibilantes no palatales aparecen como [s] y todas las sibilantes palatales como [ $]$ ]: xenio, limpessa, bassa (del verbo 'vazar'), texélla (por 'tigela'), marsinho (por 'marzinho', diminutivo de 'mar'), dissen (por 'dizem'), coussas, rixo (por 'rijo'), fasser (por 'fazer'), precisso, xá, xa, más s'elles [sic] (por 'mas eles', donde se marca la realización sorda de la sibilante final unida a la palabra siguiente), cassou, hoxe y trasseiro. La forma pexsa (por 'pesa') posee una representación grafemática peculiar, pero parece que representa igualmente el ensordecimiento de la sibilante como [s]. Finalmente es interesante referir un único caso de fricativización de la africada [t]]: fexada (por 'fechada').

3. Usa sistemáticamente el adverbio num y la conjunción se num (por 'senão'). Hay otros casos en que se señala la no pronunciación del diptongo nasal final: moons (por 'mãos'), Hortelom, eston (por 'estão'), tan, ban (por 'vão'), y los diptongos átonos de las formas verbales batan y foran. En los casos de moons, Hortelom y eston se intuye la representación del diptongo [õ̃w] como se pronuncia aún hoy en la región interamnense.

4. La consonante nasal final se pronuncia como en gallego, según se desprende de la grafía con $<$ n $>$ final, como en los 
casos acabados de referir de eston, tan, ban, batan y foran, así como en bén (por 'vem'), ten, dissen (por 'dizem'), ben (por 'vêm'), paressen, ben (por 'bem'), Entren, poden y entrassen.

5. Alteración inusual en el timbre de las vocales átonas: qua (por 'que'), texélla (por 'tigela'), Sanhor, Sanhora, esbofatiada (por 'esbofeteada'), estrabordando (por 'estrebordando') y charume (por 'chorume').

6. La alteración en los diptongos orales portugueses aparece en las variantes de 'pois' Apôes, Apoús y Apous (1819: 17), soluciones que, como se ha advertido ya, tienen que ver con la no disimilación en gallego de ou y con el vulgarismo pos. Sería este el mismo caso que en Doitores por 'Doutores', pero a la inversa. Las formas semicultas o de influencia castellana en -io/-ia, frente a las tradicionales conservadas en portugués, tiene su reflejo en esta forma irregular o caricaturesca: escadeas (por 'escadas').

7. La yod antihiática aparece en minha yama, a yaugua y com'a yella (por 'como ela').

8. En el ejemplo anterior de com'a yella encontramos la conjunción comparativa coma conservada en gallego moderno. También en comá formigas (por 'como formigas').

9. La $a$-protética aparece en este único caso: Apegue, apegue (por 'pegue, pegue').

10. Hay otros galleguismos como el uso frecuente del verbo botar, ya entonces rústico $\mathrm{y}$ arcaico en portugués, trisnuntonte (por 'anteontem') y a lá (por 'lá'). Se unen a otros vulgarismos para caracterizar la lengua de Braz: bolrinhas (por 'borlinhas') y pra. Algunas formas son difíciles de identificar: arrasmunsado y bícarenhos. La forma queixadas (por 'queixo') representa un cruce cómico con las 'queijadas' portuguesas, pues este término en boca del gallego también se pronunciaría queixadas.

En el Entremez novo O Astrologo por Nova Invençaõ (s.f.), un gallego llega a casa de un peluquero con el recado de que este se desplace a casa de su señor. Su habla solo muestra un rasgo de influencia castellana: el pronombre le por 'lhe'. En su breve intervención aparecen estos rasgos:

1. Betacismo: bestido, bem (por 'vem'), lebasse, trabessa, beja y bai.
2. Tres casos del adverbio num.

3. El pretérito de tercera persona dixe-me (por 'disse-me'), por interferencia del gallego 'dixo-me'.

Finalmente, en el Entremez novo intitulado $O$ Velho Surdo, e Peralta (s.f.) interviene un criado gallego llamado Braz cuya lengua contiene numerosos castellanismos: yo, tengo, sus mercês, estoy, perro (por 'cão'), quiero, boy (por 'vou'), boime (por 'vou-me') y pongo. Otros rasgos del texto:

1. Betacismo: bexa y Beja (por 'veja'), oybe y oibe (por 'ouve'), oibio (por 'ouviu'), oibir (por 'ouvir'), xerbillo (por 'servi-lo'), beria (por 'viria'), bem (por 'vem'), birem (por 'virem'), tibi (por 'tive'), belho, boy y boime (del verbo 'ir') y bamos.

2. Ensordecimiento en $\left[\int\right]$ de las sibilantes palatales y no palatales: Xanhor, xanhor, xenhor y xinhor (por 'senhor'); xe (por el pronombre 'se'); xe (por la conjunción 'se'); bexa (por 'veja'); faxo (por 'faço'); xou (por 'sou'); lixeiro; xenio; ixo; xerbillo (por 'servi-lo'); xeito; Xim; xem; xeu; xerto; xua y xofrello. Las formas hoyo por 'hoje' y dezeyos por 'desejos' parecen representar una pronunciación africada de la sibilante, sonido existente en gallego moderno. En mejaravel (por 'miserável'), la sonora no palatal fue sustituida por una africada sonora palatal. La forma fixeraõ por 'fizeram' parece que responde a este rasgo general de pronunciar como [S] todas las sibilantes, aunque también podría tratarse del tema de pretérito usado en la conjugación gallega de este verbo. Y eso mismo vale para estos casos del verbo 'dizer', todos de la tercera persona: dixeme, Dixe y dixe (gall. 'dixo').

3. Fricativización de la africada $\left[\mathrm{t} \int\right]$ : bixos (por 'bichos').

4. Uso sistemático del adverbio num o Num. Es el único caso del texto en que no se respeta el diptongo nasal en posición final.

5. En cuanto a las vocales átonas, llaman la atención las variantes de 'senhor' xanhor y xinhor. En tibi por 'tive' se puede intuir un momento de transición en la pronunciación de la -e final o, si la obra fue escrita a finales de siglo o a principios del siguiente, una pronunciación que ya sería percibida en Lisboa como rústica. Finalmente, en 
emcomode por 'incomode' parece que se recoge la relajación de las átonas nasales en gallego, si bien también es posible admitir la confusión en la pronunciación de en + consonante en posición inicial.

6. Hay dos casos de confusión en las tónicas, como los que se han visto anteriormente en otros textos analizados: Antunces y entances (por 'entonces').

7. En cuanto a los diptongos, hay asimilación en apoquente (por 'apouquente'). Aparece, como en otros casos, el posesivo 'mei' por 'meu', tanto en la expresión fosilizada mey amo como en meys quartos. Finalmente, un caso de disimilación se encuentra en todas las formas ya vistas del verbo 'ouvir': oybe, oibe, oibio y oibir.

8. La confusión de formas con diptongo o sin diptongo final -io,-ia aparece en la forma como Braz llama a su amo: Astolfio (por 'Astolfo').

9. Otros rasgos significativos del personaje gallego con el uso de $a$ cá (por 'cá') y muy (por 'muito'), aunque esta forma sería percibida como arcaica o rústica tanto como gallega.

Aunque en todas las obras suelen reproducirse los rasgos de estos personajes de forma no sistemática, en el caso de Braz esto sucede de forma más acentuada.

\section{Conclusiones}

La lengua de los gallegos en el teatro de cordel de Portugal es, fundamentalmente, un portugués hablado con rasgos gallegos, sobre todo fonéticos, pero salpicado de castellanismos y con numerosos coloquialismos y vulgarismos propios del portugués de la segunda mitad del siglo XVIII que nos permiten una mirada indirecta a las innovaciones que en esta lengua se estaban produciendo entonces.

Las obras estudiadas ofrecen una gran diversidad en el tratamiento del personaje y de su lengua, desde una parodia extrema, con una expresión caricaturesca y distorsionada (como en $O$ Galego Lorpa e os Tolineiros), hasta versiones más amables del personaje y con rasgos más próximos a la realidad lingüística.

En todo caso, la lengua de los gallegos no es pura invención artificial con ingredientes propios de los dialectos norteños del portugués, como suponía Menéndez (1994). Por el contrario, es posible deducir rasgos diferenciadores del gallego frente al portugués en el siglo XVIII, algunos de ellos, como hemos advertido, difíciles de documentar en este período:

a) Ensordecimiento de la sibilante palatal [3] (v.gr., xa, xenio, hoxe, oxeto) y de la predorsodental o apicoalveolar [z] (v.gr., limpessa, coussas, precisso, fasser). No se documenta una pronunciación como interdental $[\theta]$ de las africadas medievales, quizás por la dificultad de representar ese sonido, o quizás porque mayoritariamente los gallegos se adaptaban al seseo cuando hablaban en portugués. Llama la atención, por otro lado, la frecuencia con que todas las sibilantes (palatales y no palatales) son representadas indistintamente $\operatorname{con}<\mathrm{x}>$, tal vez porque esa era una pronunciación que caracterizaba de forma muy marcada a los gallegos a oídos de un portugués o porque así les sonaba también la sibilante apicoalveolar de algunos gallegos. Aparentemente, la mayor dificultad de los gallegos estaba en la pronunciación de [z], pues la palatal [3] aparece con más frecuencia correctamente representada. Incluso en algunos casos los gallegos parecen pronunciar la palatal sonora para sustituir a la predorsodental sonora lisboeta (vg.r., cojinha por 'cozinha', mugico por 'músico', trajer por 'trazer'). Algunas grafías como hoyo [sic] por 'hoje' y dezeyos por 'desejos' parecen mostrar una pronunciación africada.

b) Betacismo: de bagar, andaba, berdade, bós, bisto, etc. Hay algunos casos inversos, es decir, la pronunciación con [v] de palabras con [b]: cavrinha, vorrego, etc. Es posible que los gallegos, cuando aprendían a pronunciar este sonido, lo usasen a veces de forma impropia.

c) Ausencia de fonemas vocálicos nasales. A oídos de un portugués, la resonancia nasal de las vocales gallegas entre consonantes nasales o ante consonante nasal trabante es percibida de forma parecida a como se pronuncian esas vocales en esos mismos contextos en portugués, salvando el efecto sobre el timbre. Sin embargo, hay dos fenómenos donde cualquier portugués de la época (y también en nuestros días) percibe una gran diferencia de pronunciación: los diptongos nasales en posición final y la pronunciación en gallego de una consonante nasal en posición final de palabra. El ejemplo más paradigmático es el del adverbio 
num (con diversas variantes), pues aparece prácticamente en boca de todos los personajes gallegos en todas las piezas del teatro de cordel. Pero hay muchos más ejemplos, tanto del diptongo nasal no pronunciado (consolaçon, coraçon, som...), como de la consonante nasal, representada como $<\mathrm{n}>$ en lugar de la grafía portuguesa $<\mathrm{m}>$ (benedisson, tamen, nin, con, $\min . .$.$) .$

d) Monoptongación de [wa] en los grupos [kwa] y [gwa]: cal, cartos, canto (por 'quanto'), agardando.

e) La diferencia entre los diptongos decrecientes gallegos y portugueses hace que en boca de los gallegos aparezcan formas distorsionadas o caricaturescas (gauta por 'gaita') o reinterpretaciones, como acuidir (por 'acudir'). También aparecen asimilaciones y disimilaciones que pugnaban entonces por generalizarse en portugués.

f) Pronunciación de hiatos, recogida en vulgarismos como creada, o en formas reinterpretadas como Sua Merceia, xua mercêa, xeo (por 'seu') y beo (por 'veio').

g) Uso de la yod antihiática: a y alma, a iagua.

h) Las vocales nasales átonas sufren procesos de relajación y alteración del timbre como todas las vocales átonas, dando origen a formas como: num, im y an (por 'em'), tomben, antonces, pundero ('pondero'), etc.

i) Recuperación culta de la yod en las terminaciones -ancia, -encia, -(i)cia e -(i)cio, extendido a otros casos de final -io/-ia: estudio. Casos de hipercorrección: Angustas, terria, prodixo (por 'prodígio'), murrazios (por 'murraços'), rabios, etc.

j) Formas de la morfología verbal gallega: baya (subjuntivo de 'ir'), som y son (por 'são' o 'sou'), fum (por 'fui'), tal vez sôs (por 'sois') ${ }^{28}$, beo (pretérito de 'vir'), hai, traiga, Binhera, formas con el tema $f a g(u)$ - y fix- del verbo 'fazer', formas con el tema estuv- del verbo 'estar' (por influencia castellana), formas con el tema dix- del verbo 'dizer'.

k) Otros galleguismos: $m u i^{29}$, uso de la preposición $a$ en la perífrasis de ir $a+i n f^{30}{ }^{30}$,poscudo y poscudalla (del gallego 'pescudar'), em trementes, conjunción comparativa coma, a lá y a cá (por 'lá' y 'cá'), el vulgarismo pos (por 'pois'), entonces, medio (por 'meio'), tamen o tamem, despos (por 'depois'), trisnuntonte, impoxible. Como vulgarismos hay que considerar la abundancia de $a$ protética y la alteración de las vocales átonas (a veces exageradamente extendida a las tónicas).

1) La abundancia de castellanismos, no tanto los que se habían incorporado al gallego (y que se han señalado en el análisis de los textos) como los que escogían los emigrantes gallegos para mostrar una lengua más ilustre.

Por otro lado, también se encuentran rasgos lingüísticos de los personajes gallegos que, de forma indirecta, documentan innovaciones en curso de la lengua portuguesa, pues en la época, por ser consideradas aún meros vulgarismos, servían para marcar la lengua de los gallegos ${ }^{31}$ :

a) La generalización de la pronunciación [ẽ] en el grupo inicial en + consonante marca como vulgarismos formas como intendo, sintrumeta ('se entrometa'), imbergonhou, etc.

b) La reducción del vocalismo átono pretónico aún era percibida como vulgar e incorrecta, por lo que se marca la lengua de los gallegos con formas como custado, Siringoncias, buces (por 'vocês'), premor (por 'primor'), milhor, bistidura, apuzento, etc. Los casos de pronunciación [i] de la $e$

28 La elisión de la $d$ en la $2^{\mathrm{a}}$ persona del plural se documenta en gallego (igual que en portugués) desde el siglo XV, y fue muy abundante hasta época contemporánea, entre los siglos XIX y XX, en que declina su uso y, aunque no lo recoge el gallego normativo, aún está viva en determinadas regiones de Galicia (v. Mariño Paz 2003: 214-221).

29 Anticuada en portugués, solo aparece en boca de los personajes gallegos.

30 Aunque la perífrasis con la preposición $a$ también es posible en portugués, su uso es minoritario, antiguo o regional, y en los textos estudiados caracteriza a los gallegos. Por el contrario, en gallego también se usa la perífrasis sin la preposición, siendo preceptiva en la norma académica, pero el uso de la preposición es muy frecuente, incluso preponderante, en la lengua oral.

31 Es evidente que el largo período en el cual se escribieron estas piezas obliga a fechar cuidadosamente cada caso, pues formas que podían parecer vulgares a mediados del siglo XVIII ya eran aceptadas en la lengua culta lisboeta a finales de siglo o a principios del XIX. 
pretónica pueden representar una pronunciación rústica, frente a la que se imponía entonces como [t] en la lengua cortesana. En posición inicial absoluta encontramos casos de elisión que quizás sonasen aún muy vulgares: stum y stubera.

c) La pronunciación [i] final ya aparece como vulgar o rústica en declarisse ('declare-se'), tibi (por 'tive').

d) Emergencia de una yod ante consonante palatal: beijo (por 'vejo'), beijaõ (por 'vejam'), boixê (por 'você').

e) Desafricativización de [t $\left.\int\right]$ : muxos (por cast. 'muchos'), xamaõ (por 'chamam'), caxopas (por 'cachopas'), marxo (por 'marcho'), muxila (por 'mochila'), etc. También hay casos de hipercorrección: puchões (por 'puxões'). f) Disimilación de ou: oitra, coisa, Doitores, oibir, etc. La extrañeza ante las soluciones gallegas para algunos diptongos decrecientes hace que la lengua de estos personajes presente numerosas formas irregulares.

g) Disimilación de eu: exclusivamente en el posesivo mei, sobre todo en la expresión mei amo.

h) Asimilación del diptongo ou. Hay dos casos dudosos: las formas del tipo pous o apous en lugar de 'pois' parecen representar el vulgarismo gallego 'pos'; por otro lado, las formas apoquentem y apoquente también podrían interpretarse como castellanismos.

i) Forma coloquial munto (por 'muito'). Vulgarismos como prove (por 'pobre') o Quantes (por 'quanto a'). Regionalismos como el diptongo norteño [õw]: moons (por mãos).

\section{Obras citadas}

C., J. D. R. da [sic] (1779): Novo entremez dos Destemperos de um Basofia, jocosos, e exemplares. En la página 12: FIM. Por J. D. R. da C. LISBOA. Na Officina de MANOEL COELHO AMADO, Anno M. DCC. LXXIX. Com licença da Real Mesa Censoria.

COMEDIA NOVA, INTITULADA O NEGOCIANTE IMPRUDENTE (1792): En página 39: FIM. LISBOA: NA OFFICINA DE SIMÃo thadDEO FERREIRA. ANNO DE M. DCC. XCII. Com Licença da Real Meza da Comissão Geral sobre o Exame, e Censura dos Livros. Vende-se na mesma Officina com outras muitas mais, e varios Entremezes.

DRAMA, o GALEGo SURDo (1773): En página 15: FIM. LISBOA Na Officina DE CAETANO FERREIRA DA COSTA. Anno M.DCC.LXXIII. Com Licença da Real Meza Censoria.

ENTREMEZ INTITULADO: O VelHo PERALTA (1776): En página 1: lisboa: Na Officina de FRANCISCO SABINo DOS SANTOS. M. DCC. LXXVI. Com licença da Real Meza Censoria.

Entremez novo intitulado O Velho Surdo, e Peralta (s.f.): En página 16: Com licença da Rel Meza Censoria, S.L.

ENTREMEZ NOVO O ASTROLOGO POR NOVA INVENÇAÕ (s.f.): En página 16: LISBOA. NA OFF. DE ANTONIO GOMES. Com licença da Real Mesa da Comissaõ Geral sobre o Exame, e Censura dos Livros.

Melo, Francisco Manuel de (1660): EPANAPHORAS / DE VARIA HISTORIA / PORTUGUEZA / A / ELREY NOSSO SENHOR / D. AFONSO VI. / EM CINCO RELAÇOENS / DE SVCESSOS PERTENCENTES A ESTE REYNO. / [...] LISBOA. / Com todas as licenças necessarias. / Na Officina de Henrique Valente de Oliueria / Impressor delRey Nosso Senhor. / Anno 1660. Accesible en la Biblioteca Digital de la Biblioteca Nacional de Portugal: http://purl.pt/771.

Nova COMEDIA DE HUM ENGENHO PORTUGUEZ DENOMINADA ASSEMBLEA (1781): En la página 31: FIM DE TODA A OBRA. LISBOA. Na Officina de FRANCISCO BORGES DE SOUSA. Anno 1781. Com licença da Real Meza Censoria.

Nova PESSA, INTITULADA O MiZERAVEL ENGANAdo (1788): En página 16: LISBOA: Na Officina de Francisco Borges de Souza. Anno de 1788. Com licença da Real Meza da Comissaõ Geral sobre o Exame, e Censura dos Livros.

Novo ENTREMEZ DAS REGATEIRAS BRAVAS (1786): En página 15: FIM. LISBOA. Na Offic. Patriarcal de FRANCISCO LUIZ AMENO. M. DCC. LXXXVI. Com licença da Real Meza Censoria.

Novo entremez dos Desprezos de hum Filho Peralta a Seu Pai, ou Sophismas, com que Enganou a SUA CREADA (1774): En página 1: LISBOA, Na Officina de FRANCISCO SABINO DOS SANTOS M.DCC.LXXIV. Com licença da Real Meza Censoria.

Novo ENTREMEZ INTITULADO A CORRECÇÃO DAS VAIDOSAS (1819): En página 1: LISBOA: NA IMPRESSÃo DE ALCOBIA. 1819. Com Licença.

NOVO ENTREMEZ INTITULADO A HABITAÇAM DA LOUCUAR [sic] (1790): En página 1: LISBOA: Na Offic. de JOSE DE AQUINo bULHoENS, Anno de 1790. Com licença da Real Meza da Commissaõ Geral sobre o Exame, e Censura dos Livros. 
Novo ENTREMEZ INTITULADO CASQUILHARIA POR FORÇA (1781): En página 16: FIM. LISBOA, Na Officina de DOMINGOS GONSALVES. Anno de MDCCLXXXI. Com Licença da Real Meza Censoria.

Novo ENTREMEZ INTITULADO O GALLEGO LORPA, E OS TOLINEIRos (1808): En la página 16: FIM. LISBOA: NA tyPografia laCERDina. Anno 1808. Com licença da Meza do Desembargo do Paço.

Novo eNTREMEZ INTITULAdO O GALLEGO LORPA, E OS TOLINEIRos (1845): En la página 16: fim. lisboa: 1845.- TYP DE MATHIAS JOSÉ MARQUES DA SILVA, Rua do Ouro N. ${ }^{\circ}$ 5. Vende-se na mesma Typographia.

Novo ENTREMEZ INTITULADo Os EFFEITOS DA POEZIA VARIA (s.f.): En la página 16: LISBOA: NA OFF. DE ANTONIO GOMES. Com licença da Real Meza da Comm. Geral sobre o Ex., e Cens. Dos Livros.

\section{Referencias bibliográficas}

Barbosa, Jorge Morais (1994): Introdução ao Estudo da Fonologia e Morfologia do Português. Coimbra: Livraria Almedina.

Carrasco González, Juan M. (2010): "Traços galegos e não galegos do dialecto fronteiriço de Xalma (manhego, lagarteiro e valverdeiro)", en M. J. Marçalo, M. C. Lima-Hernandes, E. Esteves, M. do C. Fonseca, O. Gonçalves, A. L. Vilela y A. A. Silva, Língua portuguesa: ultrapassar fronteiras, juntar culturas. Actas do II SIMELP. Évora: Universidade de Évora, http://dspace.uevora.pt/rdpc/handle/10174/6722.

(2020): "La lengua de los gallegos en el teatro portugués del siglo XVIII: La obra de Manuel de Figueiredo", en A. Bernat Vistarini, A. del Olmo Iturriarte, F. J. Díaz de Castro y M. de L. Pereira (eds.), Como el camino empieza. Palabra e imagen para Perfecto E. Cuadrado. Palma: José J. de Olañeta, Editor, pp. 45-61.

Cintra, Luís Felipe Lindley (1983): "Os ditongos decrescentes ou e ei: esquema de um estudo sincrónico e diacrónico", en Estudos de dialectologia portuguesa. Lisboa: Sá da Costa, pp. 35-54 [primera versión en Anais do Primeiro Simpósio de Filologia Românica (1958), Rio de Janeiro, 1970, pp. 115-134].

Coelho, Ana Claudia Pérez (2018) “Aú, água fresca, água fresquinha: uma análise humanística sobre a figura dos galegos aguadeiros em Lisboa", Madrygal. Revista de Estudios Gallegos 21, pp. 189-204, https://doi.org/10.5209/MADR.62600.

Cruz, Duarte Ivo (2001): História do teatro português. Lisboa: Editorial Verbo.

Fernández Rei, Francisco (1990): Dialectoloxía da lingua galega. Vigo: Xerais.

Houaiss, António; Mauro de Salles Villar y Francisco Manuel de Mello Franco (2004): Dicionário Houaiss da Língua Portuguesa ( $1^{\mathrm{a}}$ reimpressão com alterações). Rio de Janeiro: Instituto Antônio Houaiss / Editora Objetiva Ltda.

Leira, Xan (2008): Historia dunha emigración difusa. 500 anos de emigración galega a Lisboa. S.1.: Acuarela Comunicación.

Mariño Paz, Ramón (2003): O idioma galego no limiar da súa renacenza. Estudo lingüístico de textos pregaleguistas (Revista Galega de Filoloxía, Monografía 2). A Coruña: Universidade da Coruña, https:// illa.udc.gal/rgf/pdf/mon 2.pdf.

(2017): Fonética e Fonoloxía Históricas da Lingua Galega. Vigo: Xerais.

Menéndez, Fernanda Miranda (1994): “A estilização do galego no teatro português do século XVIII”, en R. Lorenzo (ed.), Actas do XIX Congreso Internacional de Lingüística e Filoloxía Románicas (Universidade de Santiago de Compostela, 1989). A Coruña: Fundación "Pedro Barrié de la Maza", vol. 6, pp. 449-455.

Real Academia Galega $\left(2012^{23}\right)$ : Normas ortográficas e morfolóxicas do idioma galego. A Coruña / Santiago de Compostela: Real Academia Galega / Instituto da Lingua Galega.

Ruders, Carl Israel (2002): Viagem a Portugal. 1798-1802. Reimpressão, Prefácio e notas de Castelo Branco Chaves, Tradução de António Feijó. Lisboa: Biblioteca Nacional de Portugal, 2 vols.

Sampaio, Albino Forjaz de (1920): Subsídios para a história do teatro português: Teatro de cordel (Catálogo da colecção do autor). Lisboa: Imprensa Nacional.

Saraiva, António José y Óscar Lopes (1982): História da literatura portuguesa (12ª edição, corrigida e actualizada). Porto: Porto Editora.

Stegagno Picchio, Luciana (1969): História do teatro português. Tradução de Manuel de Lucena sobre a $1^{\text {a }}$ edição italiana [1964], corrigida e aumentada pela Autora. Lisboa: Portugália Editora, 2 vols.

Teyssier, Paul (1982): História da língua portuguesa. Tradução de Celso Cunha. Lisboa: Sá da Costa Editora.

Vázquez Cuesta, Pilar y Maria Albertina Mendes da Luz (1971): Gramática Portuguesa. Tercera edición corregida y aumentada por Pilar Vázquez Cuesta. Madrid: Gredos, 2 vols. 